$$
\because<\quad \text { or } 1819
$$

\title{
Scalling Relations for Eddy Current Phenomena
}

\author{
C. V. Dodd W. E. Deeds
}




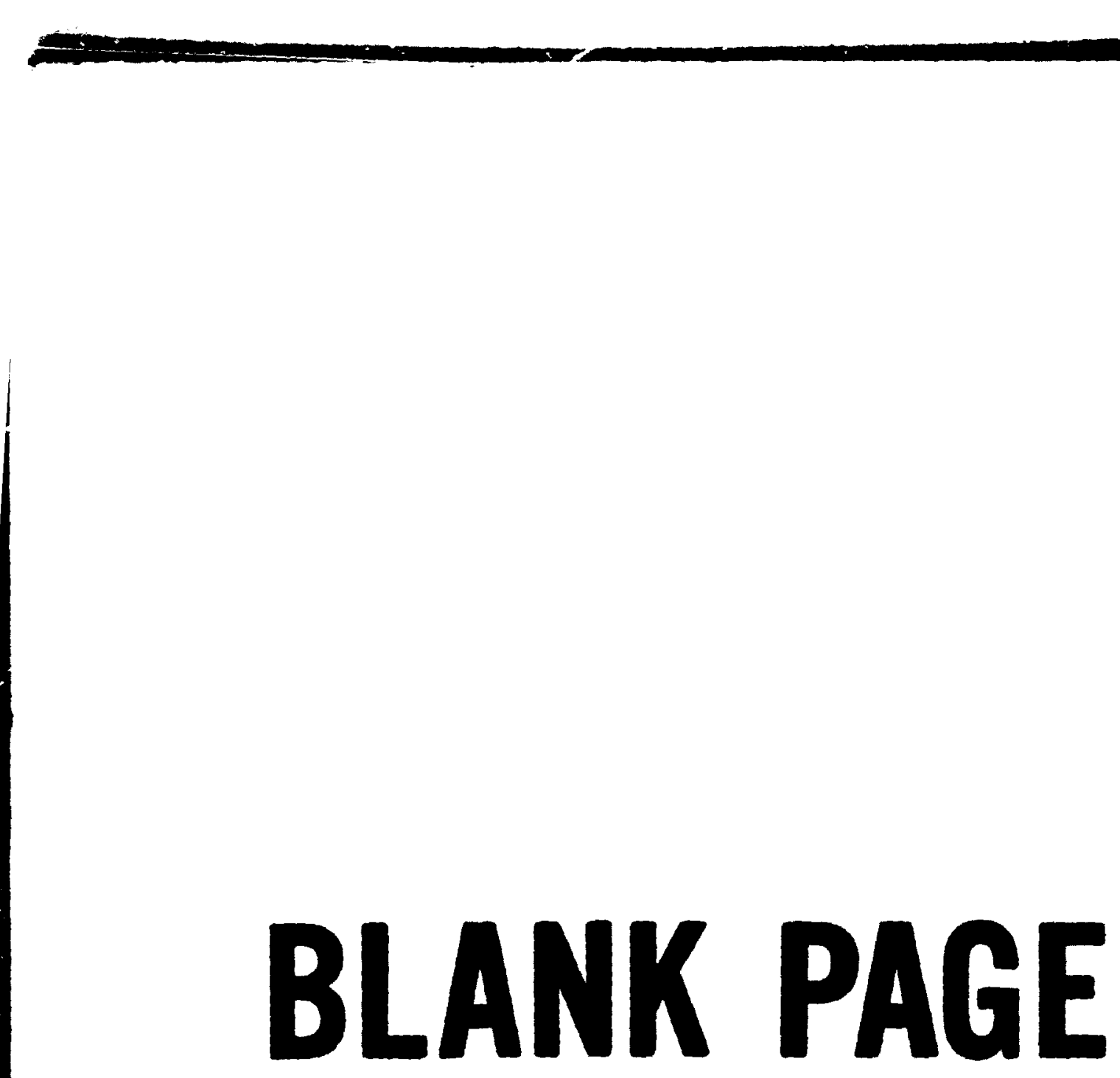




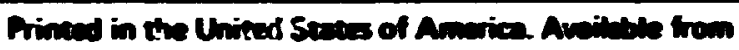
Meciond Tectwicel Information Senvice

US. Departumen of Conimere

52 s Port Royd Read, Springfied, Vinginim 22161

Price: Primad Coor SAlo: Microfiche 22.25

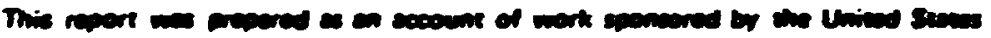

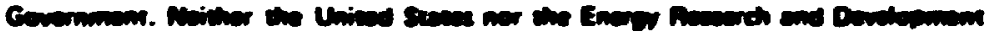

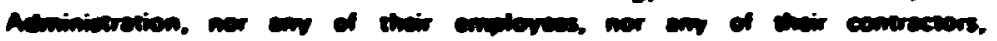

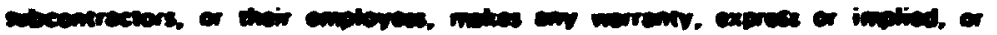

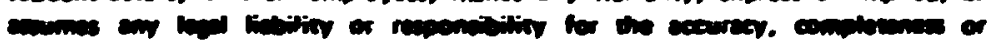

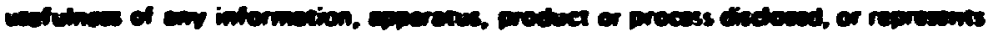

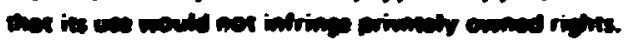




\title{
com -5077 \\ 1C-20 - controlled Trensurlear Processes and Plasen Physics
}

\author{
Contrect Ho. H-7w05-ang-20
}

intals no cenanics DIVISIO

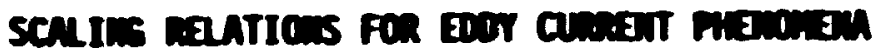

C. V. Dodd and U. E. Deeds

NOVEMBER 1975

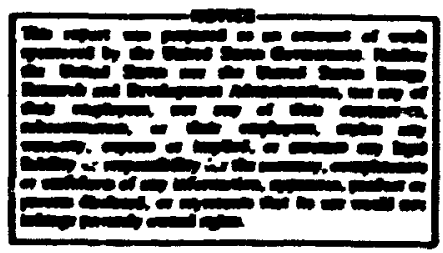

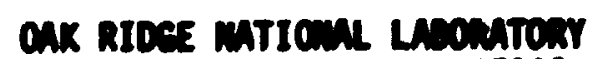

Oak Ridoe, Temiesser 37030

operated by

union caprioe coniroution

for the

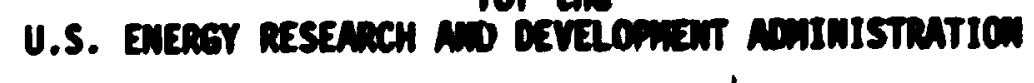




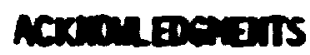

The authors wold like to express their anneciation to K. T. Yeh.

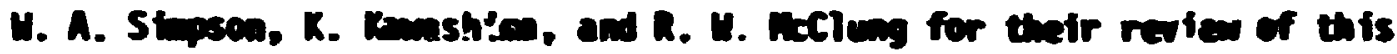
report and their mo helpfol suspations. Toy wold also libe to express their gretitude to Ance Senis. Word Processting. Techoncal Polications Departant, for the thing and prepartice of this repert. 
Comens

Pers

Intrabction ...................... I

I. Simgle Frumeacy. Scaled Equticas for the Vecter Potential .. 3

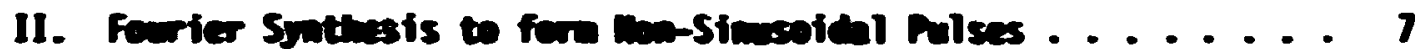

III. Mussical Prand ................. g

A. Eny Correat nasity ................ g

8. Edr Corrent punar ................ 10

c. Ingetic field ................. 11

D. Ferce dessity ................... 13

E. Voltages Induced in conpled Circuits .......... 15

F. Corrents in Multiple Conpled Circuits .......... 18

6. Driving vitugs ................ 22

IV. Measurements of the Various Properties .......... 24

A. Edy Corrent Dessity .............. 24

B. Edy corrent parer ................ 24

c. mymetic field ................ 25

D. Force Dessity ................... 25

E. Voltages in Circuits .............. 25

V. Use of Measuruments and Scaling in Licu of Calculations . . . 26

A. Nunotages of hasswrments ............ 26

B. Mventages of Calculations ............ 26

VI. Expertmental Verification of Scaling .......... 27

vII. Sunary and conclustions ............... 33

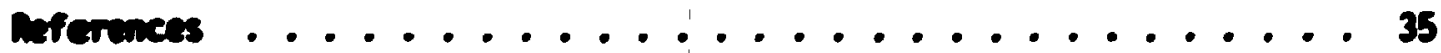




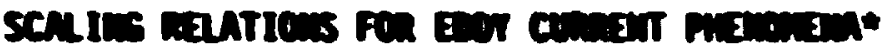

\author{
C. V. Dous and M. E. Deadsto \\ Metals and Coremies Olvistion

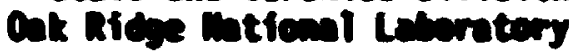

\section{Astrect}

Formule are given for various electromenetic pentities for cofls in the presence of combeters, with the scalling pareneters fectored out so that spill-scale noll experinents can be related to lary-scale smaretus. Particular enmsis is given to such quantities as ens correat mation. forces. power. and iaduced mometic fields. For axially ssmetric probless. closed-form integrals are avilable for the vector potential and all the other pentities chtaimble from it. For unsymmetrical problens, a three-dinasstemal relaration progran can be used to obtain the vecter potentiol and then the derivable quanticies. Dats on expertimental masuremints are given to verify the validity of the scaling lams for forces, inductances, and inpedonces. Indirectiy these also support the validity of the scaling of the rector potential and all of the other quantities obtained from it.

\section{Introduction}

Scaling of eddy current nondestructive testing problems has been used for many years, for both analytical calculations and experimental measurements. ${ }^{1-7}$ In the analytical calculations, we reduce the configuration to dimensioniess ratios, perform all the calculations using pure numbers, and only introduce difmensions in the final step. In the experimental mensurements, we perfon the masurements on modeis that are usually larger than the actual test so that the dilmensions can be more accurately controlled.

\footnotetext{
* Funding provided by the Superconducting Magnet Development Progrem of the Thermonuclacer Divistion. *Consultant from The University of Tennessee, Knoxullle, Tennessee.
} 


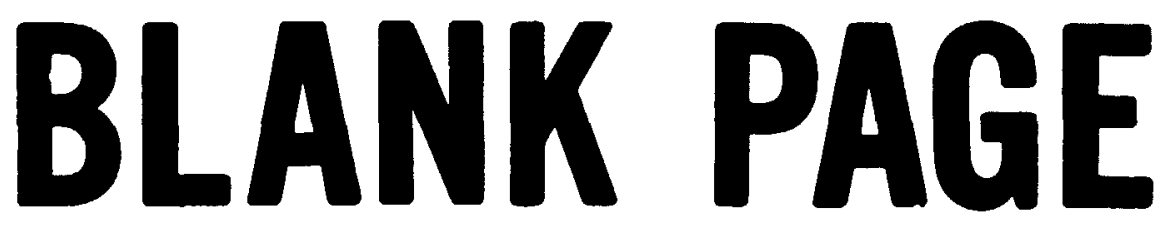


We have started our analysis with the vector potential, and can obtain closed form integral equations for it for may of the simpler cases. These apations can be quickly evaluated on a sall digital computer.

For more conplicated problems in must use a relaxation or finite difference tecturige, in elther 2 or 3 dinensions. This techinique requires a large digital computer for mancical evaluation. Once the vector potential has deternimed for verious discrete frequencies it can be calculated for any piece-wise contimous move-shape using Four?er synthesis. Fron the vector potantial any induction phenomenon can be calculated. These calculations genarally fawolve the muerical evalustion of mitiple integrals mich involve fonctions of the vector potential. As an alternative to menerical calculations, in many instances we can use masuraments on a model to evaluste the mitiple integrals. A muber of successful designs have been completed using these techniques. $0^{0-13}$ 


\section{Simle Frerneacy, Sealed Equations for the Vecter Potential}

An axially symetric coil of rectangular cross-section above multiple parallel planes is shom in fig. 1. The closed form integral equation for the vector potential produced by such a coil is, in the n-th region:

$$
\begin{aligned}
A^{n}(r, z)= & n I_{u_{0}}\left\{\left[\frac{1}{2\left(R_{2}-R_{1}\right) L_{3}}\right] \int_{0}^{\infty} \frac{J\left(R_{2}, R_{1}\right) J_{1}(a r)}{a^{3} v_{22}\left(k_{1}\right)} e^{-a\left(L_{2}+L_{6}\right)}\right. \\
& \times\left[1-e^{\left.\left.-\alpha L_{3}\right]\left[v_{12}(n, 1) e^{-a^{2}}+v_{22}(n, 1) e^{a n^{2}}\right] d a\right\} .}\right.
\end{aligned}
$$

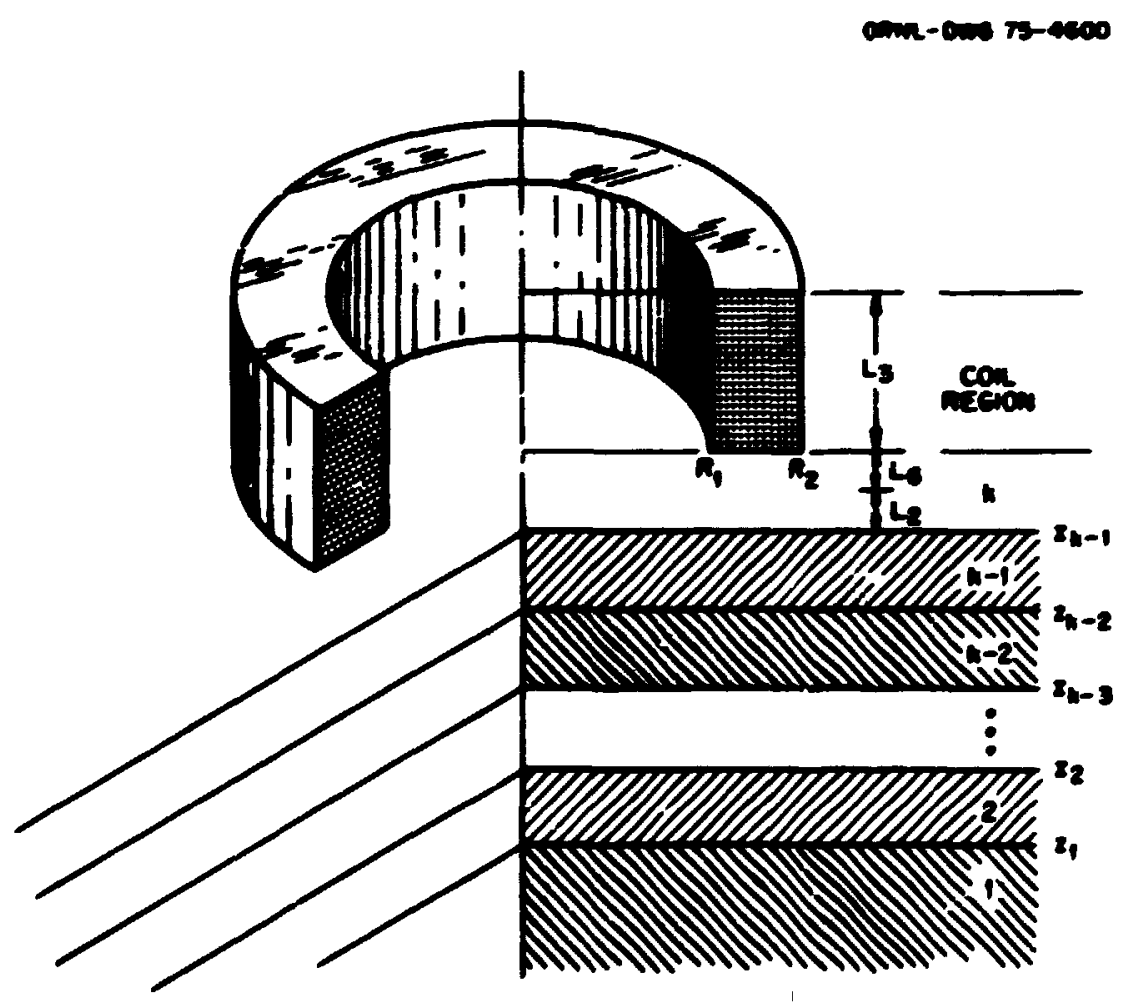

Fig. 1. Cotl Above Multiple Planes. 
The terms in brackets are completely dimenstionless. Thay are a function of the linear dimensions divided by scaling factor (uswally the mean radius of a coil of interest, R5). The frequency enters only through the function unats ${ }^{2}$, which is also dimenstionless and mould uswally be kept constant in scaling a model. The terns containing the frequency are:

$$
a_{n}=\sqrt{a^{2}+j \operatorname{mon}_{n} \sigma_{n} R_{s}^{2}}
$$

and

$$
B_{n}=\frac{1}{u_{n=l}} \sqrt{a^{2}+j w_{n} \sigma_{n} R_{5}^{2}} \text {. }
$$

Both of these terms are dimensionless.

The terns $\frac{V_{12}(n, 1)}{V_{22}(k, 1)}$ contain an equal muber of $B_{n}$ 's in both the mumerator ard denominator and are dimensionless.

we can also obtain the vector potential for any irregular coils and conductors using a three-diaensional relaxation technique. Using Cartesion coordinates, as shown in fig. 2, we find for the three components of the vector potential in non-ferromgnetic media:

$$
\begin{aligned}
& A_{x_{k l n}}=\left[\mu_{0} u \frac{\delta_{c} \cos a_{z}}{n^{2}\left(R_{2}-R_{1}\right) L_{3}}+\frac{\sigma_{k}}{\sigma_{k+1}} A_{x_{k+1}}+A_{x_{k-1}}+A_{x_{l+1}}+A_{x_{l-1}}\right. \\
& \left.+A_{x_{m+1}}+A_{x_{m-1}}+\left(\frac{\sigma_{k}}{\sigma_{k+1}}-1\right)\left(A_{y_{l+1}}-A_{y_{2}}+A_{z_{m+1}}-A_{z_{m}}\right)\right] \\
& +\left[5+\frac{\sigma_{k}}{\sigma_{k+1}}+\frac{j_{\omega \mu \sigma_{k}}{ }^{2} R_{5}^{2}}{n^{2}}\right] \text {. }
\end{aligned}
$$


5

$\operatorname{com}$ ans rs-cose

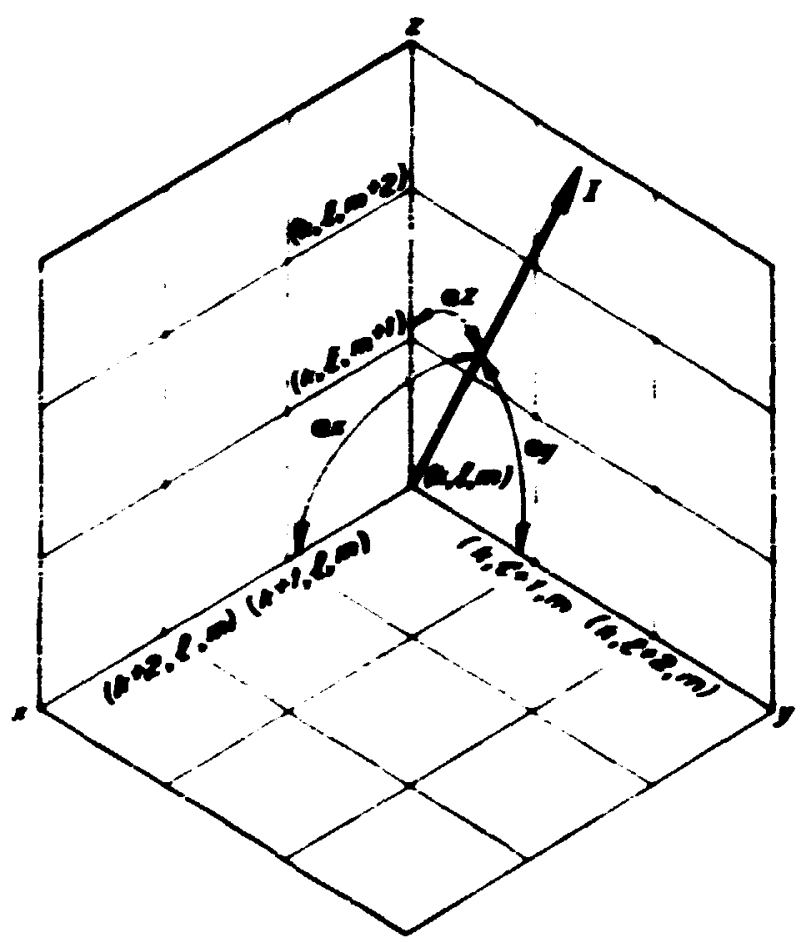

Fig. 2. Cartesian Coordinates for Three-Dilmensional Relaxation.

$$
\begin{aligned}
& A_{y_{k L n}}=\left[\omega_{0} N I \frac{{ }_{c} \cos a_{y}}{n^{2}\left(R_{2}-R_{1}\right) L_{3}}+\frac{\sigma_{l}}{\sigma_{l+1}} A_{y_{l+1}}+A_{y_{l-1}}+A_{y_{m+1}}+A_{y_{m-1}}\right. \\
& \left.+A_{y_{k+1}}+A_{y_{k-1}}+\left(\frac{\sigma_{l}}{\sigma_{l+1}}-1\right)\left(A_{z_{n+1}}-A_{z_{m}}+A_{x_{k+1}}-A_{x_{k}}\right)\right] \\
& +\left[5+\frac{\sigma_{l}}{\sigma_{l+1}}+\frac{j \omega \sigma_{k L_{n}} R_{5}^{2}}{n^{2}}\right]
\end{aligned}
$$




$$
\begin{aligned}
& A_{z_{k L n}}=\left[u_{0} \| \frac{\delta_{c} \cos a_{z}}{n^{2}\left(R_{2}-R_{1}\right) L_{3}}+\frac{\sigma_{m}}{J_{m+1}} A_{z_{m+1}}+A_{z_{m-1}}+A_{z_{k+1}}+A_{z_{k-1}}+A_{z_{l+1}}+A_{z_{l-1}}\right. \\
& \left.+\left(\frac{\sigma_{m}}{a_{m+1}}-i\right)\left(A_{x_{k+1}}-A_{x_{k}}+A_{y_{l+1}}-A_{y_{l}}\right)\right] \\
& \div\left[5+\frac{\sigma_{m}}{\sigma_{m+1}}+\frac{j w 1 n_{k m_{m}^{2} s^{2}}}{n^{2}}\right]
\end{aligned}
$$

where

$\mu_{0}$ is the magnetic permeability of free space $\left(4 \pi \times 10^{--}\right)$,

$N$ is the number of turns in the coil,

$I$ is the current per turn, and any subscript not aritten is assuned to be $k, l, m$, as the case might. be.

All other terms are dimensionless, and the vector potential is directly proportional to the source terms, woll. The quantity $d_{c}$ is equal to 1 if the lattice point is iaside the coil, zero if it is outside. $a_{x}$ is the angle between the wire direction and the $x$ axis; $R_{5}$ is the coil mean radius; $n$ is the number of lattice points in the cofl mean radfus $R_{5} ; N_{x}$ " is the number of lattice points in the cofl as the coil passes through the plane perpendicular to the $x$-axis; and the term $\omega \mu \sigma_{k} m_{m}^{R}{ }^{2}$ is dimensfonless. 
From these equations, the vector potential at each point can be obtained using a relaxation process.

The dimensionless numerical answer so determined will depend on:

1. The coil and conductor geametry;

2. The value of wroRs ${ }^{2}$.

The dimensioned factors multiplying the dimensionless mmerical answer will be nolli.

\section{Fourier Synthesis to Form Mon-Sinusodial Pulses}

Thus far, the vector potential for a single frequency, w, has been obtained. We shall now superpose a number of different frequencies to obtain the vector potential of a pulse, such as fllustrated in Fig. 3 , by Fourier synthesis. If the current is piecewise continuous and has a repetition period $T$, we can write the current waveform as

$$
I(\tau)=I_{0}\left\{\frac{a_{0}}{2}+\sum_{m=1}^{\infty} a_{m} \cos \left(m \omega_{1} \tau\right)+b_{m} \sin \left(m \omega_{1} \tau\right)\right\} .
$$

where $\omega_{1}=2 \pi / T$,

$$
a_{m}=\frac{\omega_{1}}{\pi} \int_{-T / 2}^{T / 2} \frac{I(\tau)}{I_{0}} \cos \left(m_{1} \tau\right) d \tau \quad m=0,1,2,3 \ldots \ldots,
$$

and

$$
b_{m}=\frac{\omega_{1}}{\pi} \int_{-T / 2}^{T / 2} \frac{I(\tau)}{I_{0}} \sin \left(m_{1} \tau\right) d \tau \quad m=1,2,3 \ldots-
$$


onstong is - cens

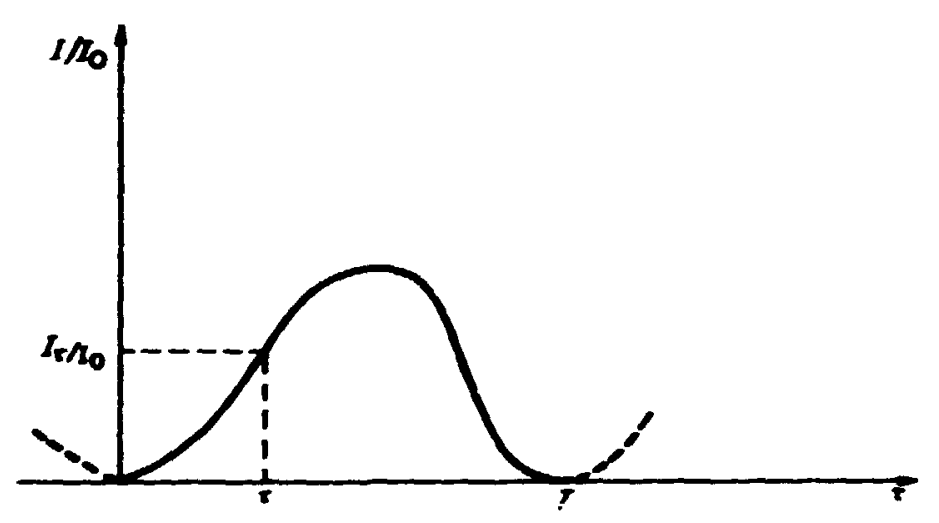

Fig. 3. Diagran of Current Pulse.

From the current, the vector potential as a function of time can be calculated:

$$
\begin{aligned}
& A(\tau)=\omega_{0} I_{0} \pi\left\{\frac{a_{0}}{2} \bar{A}(0)+\sum_{m=1}^{\infty} a_{m} \bar{A}(m) \cos \left(m_{1} t+n_{m}^{\prime}\right.\right. \\
& +b_{m} \lambda(m) \sin \left(m_{1} t+s_{m}^{\prime}\right\},(10)
\end{aligned}
$$

where $\lambda(m)$ is the vector potential calculated at the angular frequency mow with the noI $I_{0}$ factored out. $\lambda(m)$ is completely dimensioriess and 
depends only on the geanetry and the values of the products muluags ${ }^{2}$. The value of $w_{1}$ can be varied to compensate for changes in o and $R_{S}$. The value of $t$ must then be varied so that the product $\omega_{1} \tau$ is constant. Thus, the pulse in real tine $t$ my vary for the scaled rodel. The

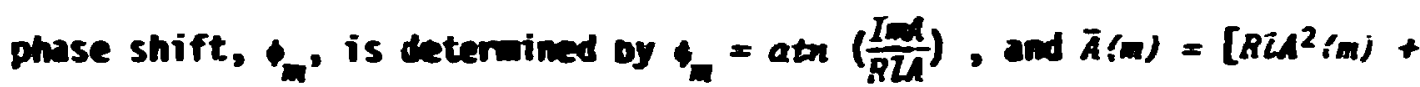
In $\left.A^{2}(m)\right]^{1 / 2}$. We shall rewrite the equation for $A(\tau)$ as

$$
A(\tau)=\mu_{0} I \pi(\tau)
$$

miere

$\bar{A}(\tau)$ is the dimensionless su given in curly brackets in Eq. (10).

From the vector potential we can calculate all the physically observable phenomena.

\section{Phystcal Phenomena}

A. Eddy Current Density

$$
\vec{J}=\sigma \vec{E}=-\sigma \frac{\vec{\mu}}{\partial \tau} \text {. }
$$

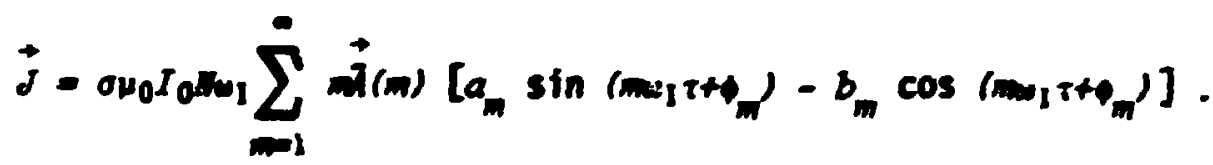


The total current passing through a normalized area, $d_{n}$, in teres of the actual area, $d^{*}=\left(d A^{\circ} / R_{s}{ }^{2}\right) R_{5}{ }^{2}=d_{n} R_{5}^{2}$, is given by

$$
\begin{aligned}
& \vec{J}_{A}=I_{0} d U_{n}\left(\omega_{1} \mu_{0} \sigma R_{5}^{2}\right) \sum_{m=1}^{\infty} \vec{i}(m)\left[a_{m} \sin \left(m_{1} j+\theta_{m}\right)\right. \\
& \left.-b_{m} \cos \left(m_{1} \tau+\varphi_{m}\right)\right] .
\end{aligned}
$$

The only dibensions are contained in the $I_{0}$. All the other terns are dimensicaless and normalized.

\section{B. Eddy Current Power}

The eddy current power dissipated per unit volume is:

$$
\frac{d D}{d v}=J \cdot E=\sigma\left(\frac{\partial A}{\partial \tau}\right)^{2}
$$

The instantaneous poumr dissipated in a normalized volume, $d v_{n}$, is

$$
\begin{aligned}
& P=I_{0}^{2} n^{2} w_{1} \mu_{0} R_{5} d V_{n z}\left(w_{1} v_{0} O R_{5}{ }^{2}\right)
\end{aligned}
$$

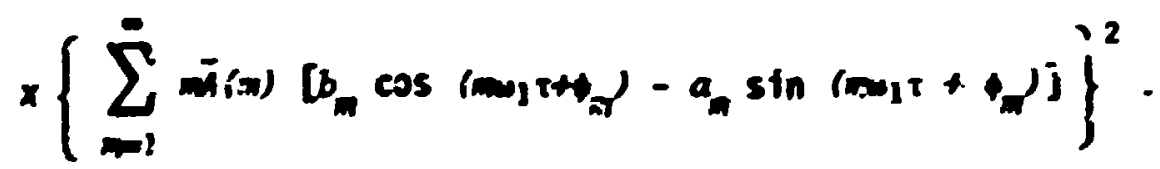

hagin, all dimansions are contained in the terns $I_{0}{ }^{2} w_{1} \mu_{0} R_{s}$, and the others are dimenstoniess. 
If there are several different coposents of the vector potentiai, the total power will contain the sua of the squares of the time derivatives of all of the components of the vector potential. That is:

$$
\frac{d P}{d V}=0\left\{\left(\frac{\partial A_{x}}{\partial T}\right)^{2}+\left(\frac{\partial A_{y}}{\partial T}\right)^{2}+\left(\frac{\partial A_{z}}{\partial T}\right)^{2}\right\}
$$

\section{Magnetic Field}

$$
\vec{B}=\nabla \times \vec{A}
$$

The exact form of the curl of $t$ depends on the coordinate system in wich $\vec{A}$ and $\vec{B}$ are computed. Usting symbols defined by Morse $\&$ Feshbach and shom in Fig. 4, we have:

$$
\vec{B}=\nabla \times \vec{A}=\frac{1}{h_{1} h_{2} h_{3}} \sum_{j, k_{2} l} h_{j} \hat{\alpha}_{j}\left[\frac{\partial}{\partial \xi_{k}}\left(h_{l} \hat{k}_{l}\right)-\frac{\partial}{\partial \xi_{l}}\left(h_{k} A_{k}\right)\right] \text {. }
$$

The difuensions of $\vec{B}$ will be $\vec{A} /$ length.

In general, we will have for the components of the mognetic field:

$$
B_{j}=\mu_{0} I_{0} \pi \frac{h_{j}}{h_{1} h_{2} h_{3}}\left[\frac{\partial}{\partial \varepsilon_{k}}\left(h_{i} \bar{\lambda}_{2}(\tau)\right)-\frac{\partial}{\partial \xi_{2}}\left(h_{k} \bar{\lambda}_{k}(\tau)\right)\right] .
$$

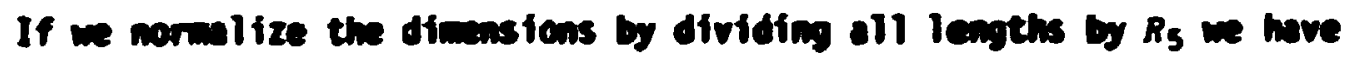

$$
B_{j}=\frac{\mu_{0} I_{0}}{h_{5}} \frac{h_{j}}{h_{1} h_{2} \bar{h}_{3}}\left[\frac{\partial}{\partial \xi_{k}}\left(h_{\tau} \bar{\Lambda}_{2}(\tau)\right)-\frac{\partial}{\partial \xi_{2}}\left(h_{k} \lambda_{k}(\tau)\right)\right] .
$$




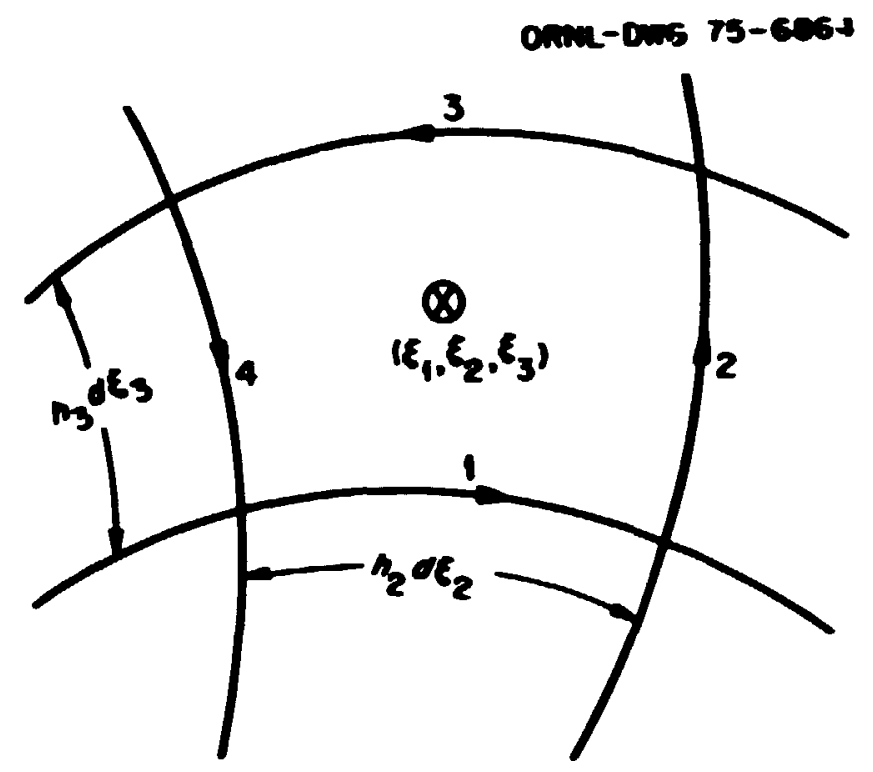

Fig. 4. Curl in Curvilinear Coordinates.

For the special case of an axially ssmetric coil above plane layers of conductor as shom in Fig. I with only a e-component of the vector potential, the expressions for the 2-component of the magnetic field in the $n$-th region (in terms of the variables used in the computer program) is: 


\section{3}

$$
\begin{aligned}
B_{z}^{n}(r, z)= & \frac{n_{3} I_{9} \nu_{0}}{2\left(R_{2}-R_{1}\right) L_{3} R_{5}} \int_{0}^{\infty} \frac{e^{-a L_{6}} e^{-a L_{2}}}{a^{2}} J\left(R_{2}, R_{1}\right)\left[1-e^{-a L_{3}}\right] \\
& x J_{0}(a r)\left\{\frac{\nabla_{12}(n, 1)}{V_{22}(k, 1)} e^{-a z^{z}}+\frac{v_{22}(n, 1)}{V_{22}(k, 1)} e^{a n^{2}}\right\} d a .
\end{aligned}
$$

The $\mathbf{r}$ component is given by:

$$
\begin{aligned}
& B_{p}^{n}(r, z)=\frac{n_{3} I_{9 U_{0}}}{2\left(R_{2}-R_{1}\right) L_{3} R_{5}} \int_{0}^{\infty} \frac{e^{-\alpha L_{6}} e^{-\alpha L_{2}}}{a^{3}} J\left(R_{2}, R_{1}\right)\left[1-e^{-\alpha L_{3}}\right] \\
& x d_{1}(a)\left\{-\frac{v_{12}(n, 1)}{V_{22}(k, 1)} a_{n} e^{-a_{n}{ }^{2}}+\frac{v_{22}(n, 1)}{v_{22}(k, 1)} a_{n} e^{a_{n}^{2}}\right\} d a .
\end{aligned}
$$

\section{Force Density}

For non-ferromanetic aterials we have for the force density:

$$
\frac{d \vec{P}}{d \vec{v}}=\vec{J} \times \vec{B}=-0 \frac{\partial \vec{t}}{\partial \tau} \times(\nabla \times \vec{A})
$$

For the $j$ th component of force in a norralized wolum

$d v_{n}=h_{1} h_{2} h_{3} d \xi_{1} d \xi_{2} d \xi_{3}$ we have 


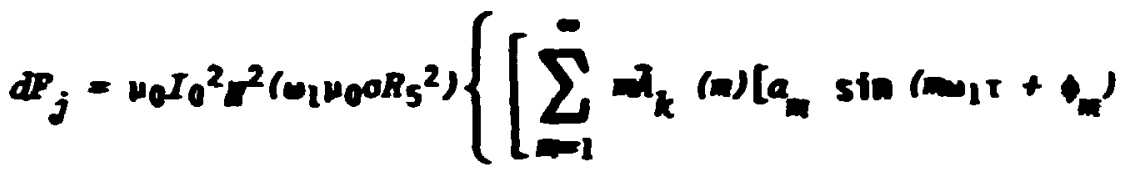

$$
\begin{aligned}
& \left.-b_{m} \cos \left(m_{1} \tau+\phi_{m}\right)\right] \quad h_{2}\left[\frac{\partial}{\partial \varepsilon_{j}}\left(h_{k} \lambda_{k}(\tau)\right)-\frac{\partial}{\partial \varepsilon_{k}}\left(h_{j} \lambda_{j}(\tau)\right)\right] \\
& -\left[\sum_{k=1}^{\infty} m_{2}(m)\left[a_{m} \sin \left(m_{1} \tau+\phi_{m}\right)-b_{m} \cos \left(m_{1} t+\phi_{m}\right)\right]\right]
\end{aligned}
$$

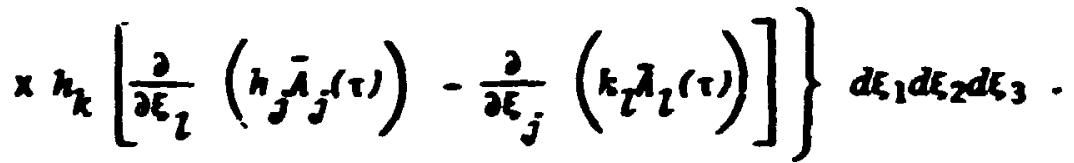

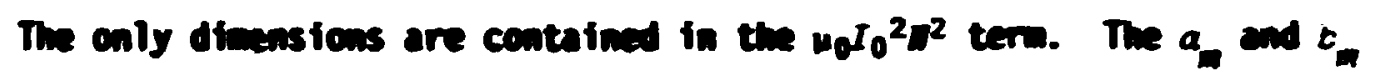
terns depend on the relative polse shape. and the A(i) terms depend on

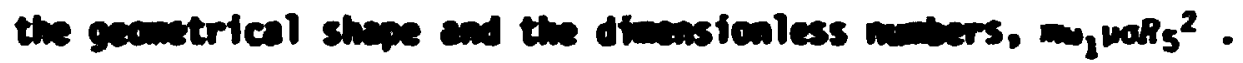

If in evalute the a compenent of force in cylfotrical coordinates move:

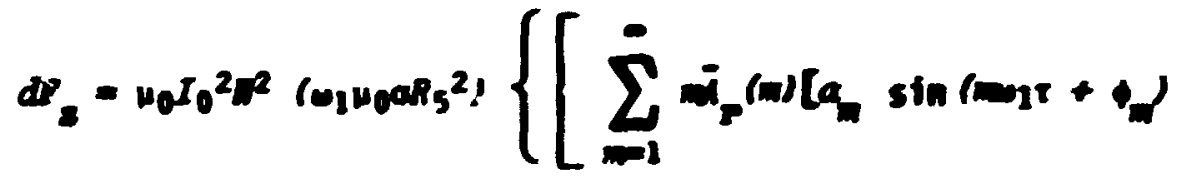

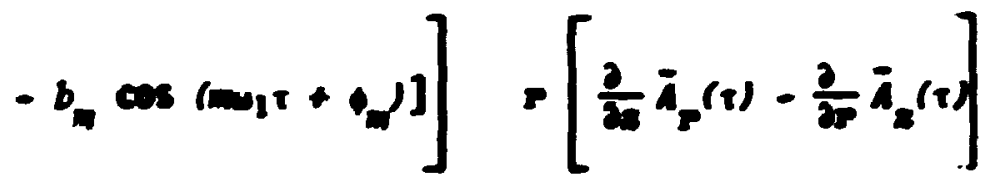

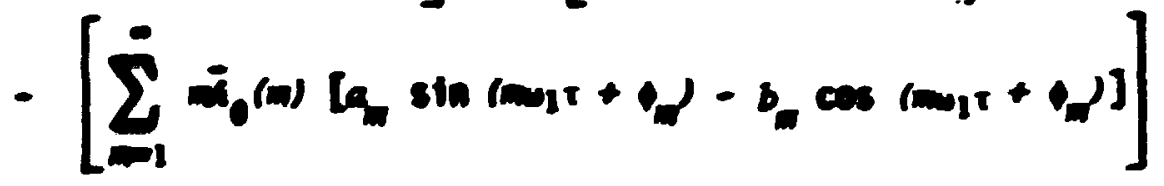

$$
\begin{aligned}
& \left.x\left[\frac{2}{25} i_{8}(\pi)-\frac{2}{2 \pi}\left(m_{0}(r)\right)\right]\right\} \text { ind }
\end{aligned}
$$


E. Voltages Induced in compled Circuits

The voltage induced in a length of vire is

$v=\int \frac{\vec{M}}{\partial t} \cdot d$

The gemeral expression for the witage faluced in coil i by a current $I_{2}$ flowing in coil 2, as shan in Fig. 5, is:

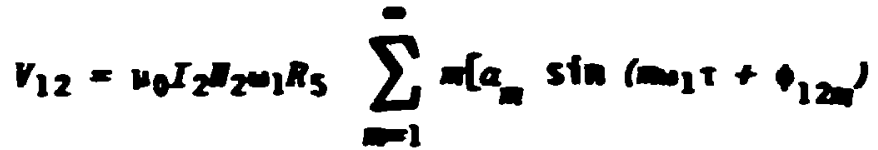

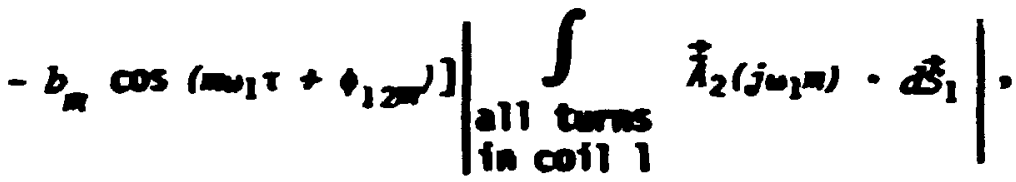

mere

$$
n_{12}=\operatorname{atn}\left(\frac{\ln \int_{1} \vec{\lambda}_{2}\left(j u_{1} m\right) \cdot \dot{d} \vec{s}_{1}}{m \int_{1} \vec{\lambda}_{2}\left(j u_{2} m\right) \cdot d \vec{s}_{1}}\right) .
$$

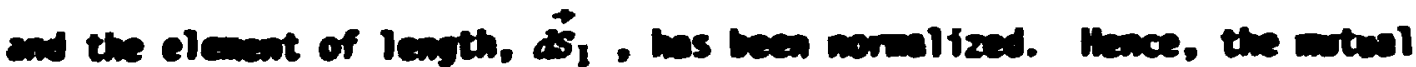
indectence of the the colls is:

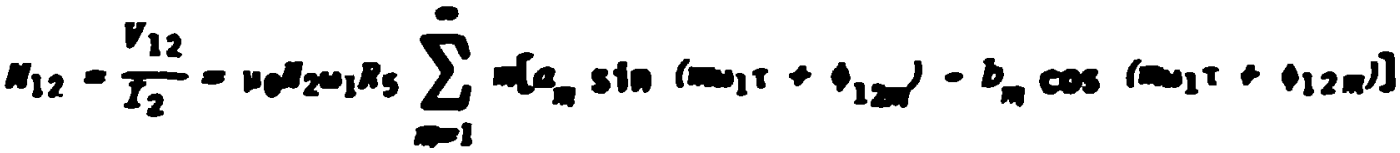

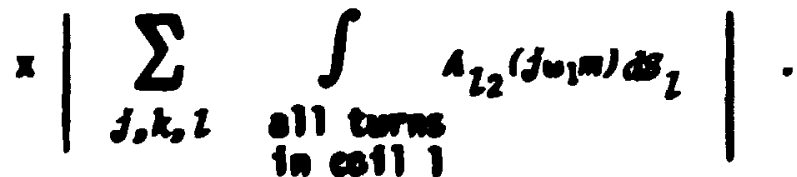




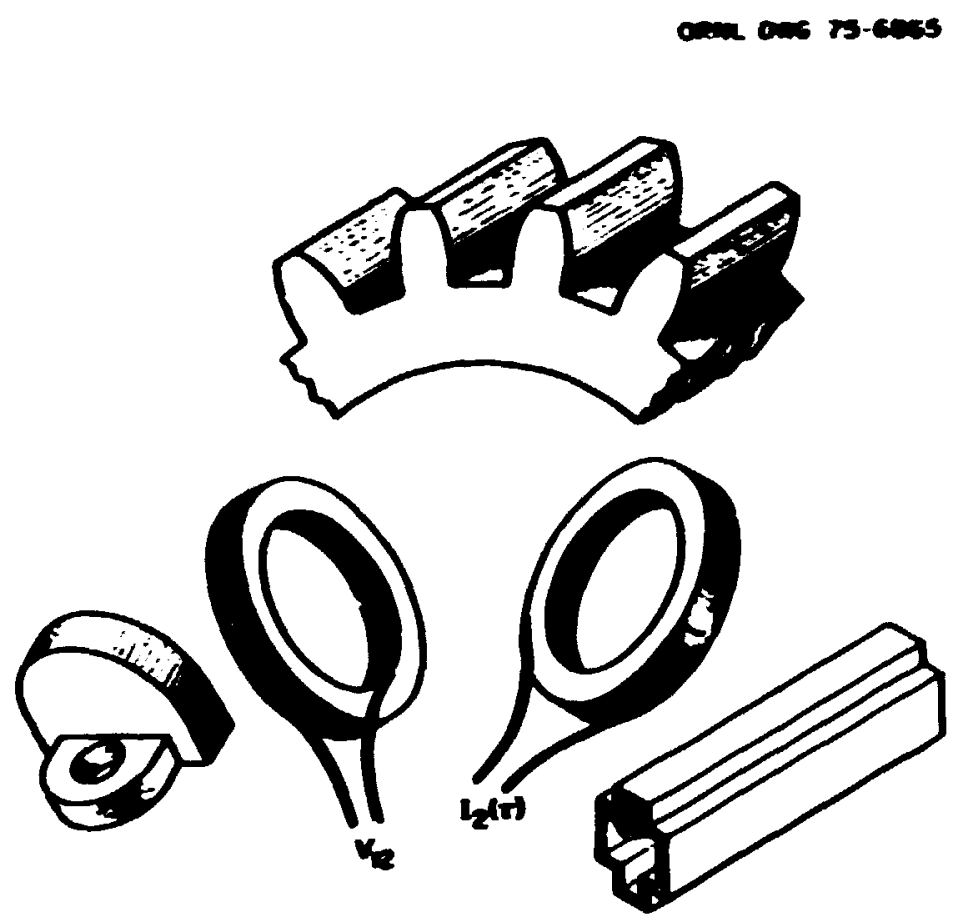

Fig. 5. Colls in the Presence of Arbitrary Conbeters.

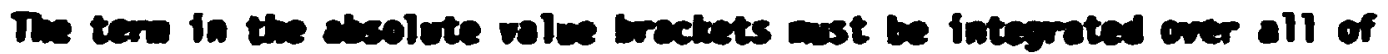

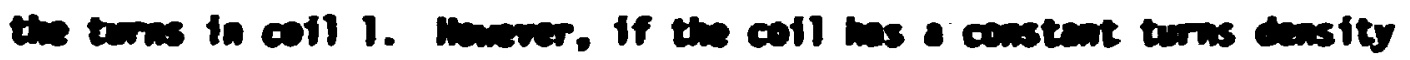
oner its eress-section we can stiplify the term to:

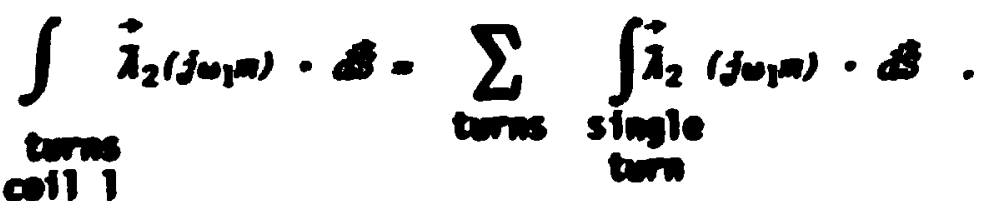

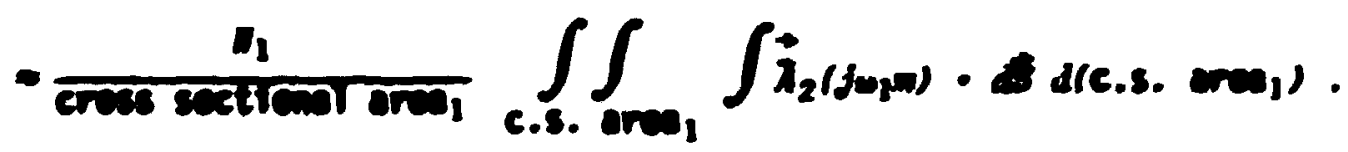


Therefore,

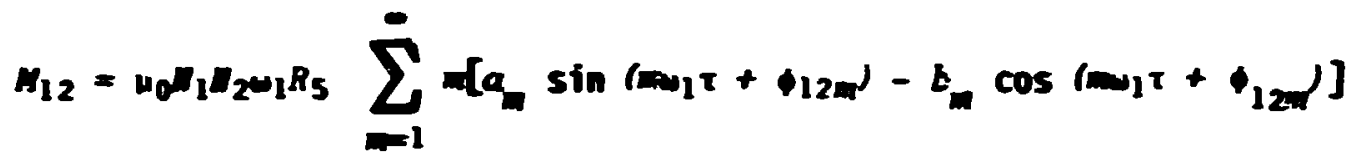

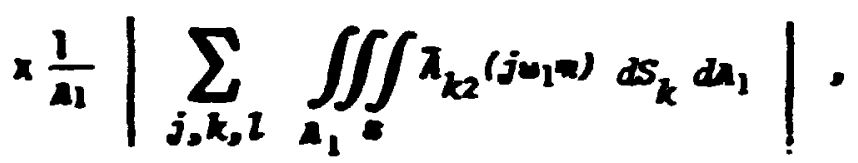

Where $A_{1}$ is the crossectional area of the coil, perpendicular to the direction of the turns. The dimensicms of $a_{1}$ will cancel those of $d_{1}$. For censistexcy we shall tabe wh to be mormilized. If as is taken along one coordinate, the simention over $2, \mathrm{~m}$ end r reduces to

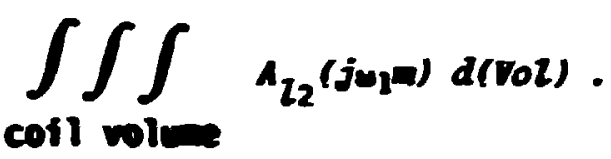

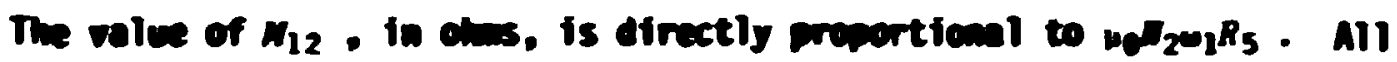

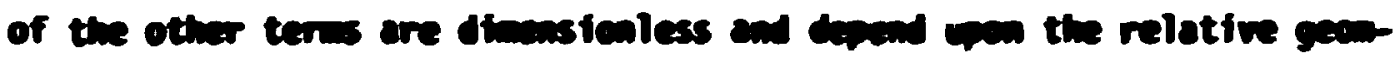
etry and the sture of the carrent wore form. The voltage incuced in the

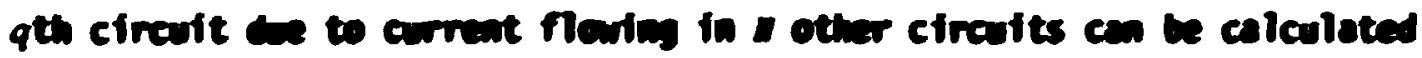
by the anotion.

$$
v_{q}=\sum_{p=1}^{D} n_{q p} I_{p}+I_{q}^{R} q
$$


Furthenore the terms in the expression can be witten as

$$
\begin{aligned}
& v_{q}=\sum_{p}^{n} \mu_{0} I_{r} H_{q} M_{r} R_{5} \sum_{m=1}^{\infty} m_{m}\left[a_{m} \sin \left(m_{1} \tau+q_{m p}\right)\right.
\end{aligned}
$$

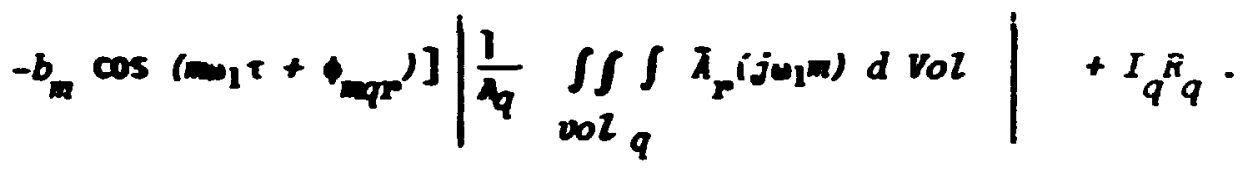

F. Currants in nultiple coupled Circuits

Un shall define a coupling coefficient with the following equation:

$$
c_{m q P}=\frac{u_{0} \|_{q} \omega_{1} R_{5}}{n_{q}}\left|\int_{\nu 0 l}^{\int} \iint \pi_{q}\left(j \omega_{1} m\right) d v o l\right|
$$

and define the $a_{n}$ coefficient for the current in the rth coil as

$$
a_{m}=a_{m}
$$

The current loop equation for the qth loop for $I$ coils then becomes:

$$
\begin{aligned}
& v_{q}(\tau)=a_{q 0} I_{q} R_{q}+\sum_{i=1}^{D} \sum_{i=1}^{D} I_{p}\left\{a _ { T m } \left[R_{q}^{\delta} q_{q} \sin \left(m_{1} \tau\right)\right.\right.
\end{aligned}
$$

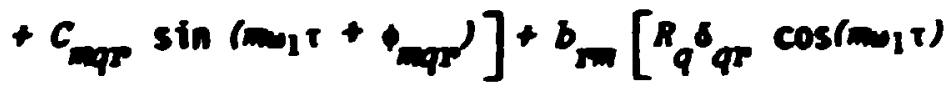

$$
\begin{aligned}
& \left.\left.+c_{m p r} \cos \left(m_{1} t+t_{m p}\right)\right]\right\} \text {. }
\end{aligned}
$$


We have assuned that the current wre shapes can be represented by a finite muber of terns, ${ }^{\prime}$. We can use the orthogonal properties of the trigometric functions to solve for the $a_{m}$ and $b_{m}$ coefficients. We shall mitiply eq. (37) by $\sin \left(m_{1}\right)$, integrate from 0 to I (the period of the periodic function, $\left.T=2 \pi / v_{1}\right)$, and use the following relationships to simplify the equations:

$$
\begin{aligned}
& \sin \left(m_{1} \tau+t_{q q}\right)=\sin \left(m_{1} \tau\right) \cos \left(\phi_{q q}\right)+\cos \left(m_{1} r\right) \sin \left(t_{m_{q}}\right)
\end{aligned}
$$

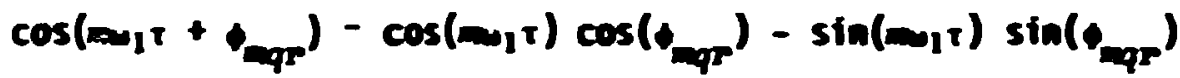

$$
\begin{aligned}
& \int_{0}^{2 \pi / \omega_{1}} \sin \left(m_{1} r\right) \sin \left(m_{1} r\right) d \tau=\frac{\pi}{2} \delta=\frac{\pi}{-1} \varepsilon \\
& \int_{0}^{2 \pi / 0_{1}} \cos \left(m_{0}, \tau\right) \cos \left(m_{1}, \tau\right) d \tau=\frac{T}{2} d=\frac{\pi}{\sigma_{1}} d \pi \\
& \int_{0}^{2 \pi / u_{1}} \sin \left(m_{1}, \tau\right) \cos \left(n \omega_{1} t\right) d t=0 .
\end{aligned}
$$

Using these relatienships, we obtain:

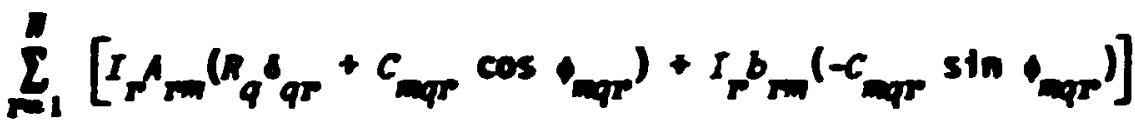

$$
\begin{aligned}
& =\frac{1}{\pi} \int_{0}^{T} v_{q}(\tau) \sin \left(\operatorname{mos}_{1} t\right) d t .
\end{aligned}
$$


20

Similarly, if we multiply eq. (37) by $\cos \left(m_{1} x\right)$ and integrate from 0 to $2 \pi / \omega_{1}$, we can obtain:

$$
\begin{aligned}
\sum_{r=1}^{n}\left[I_{r} a_{r m}\left(c_{m q p} \sin \phi_{m q r}\right)+\right. & \left.I_{r} b_{r m}\left(R_{q}^{\delta} q_{r}+c_{m q r} \cos \phi_{m q r}\right)\right] \\
& =\frac{\omega_{1}}{T} f^{T} v_{q}(\tau) \cos \left(m_{1} r\right) d \tau .
\end{aligned}
$$

For each angular frequency component, $m_{1}$, there will be $\|$ equations of the form of eq. (43), one for each of the coils, designated by q:

$$
\begin{aligned}
& I_{1} a_{1 m}\left(R_{1}+C_{m 11} \cos \phi_{m 11}\right)+\ldots+I_{n} a_{m m}\left(c_{m 1 n} \cos \phi_{m 1 n}\right) \\
& +I_{1} b_{1 m}\left(-c_{m 11} \sin \phi_{m 1}\right)+\ldots+I_{n} b_{m m}\left(-c_{m 1 n} \sin \phi_{m 1 n}\right) \\
& =\frac{\omega_{1}}{\pi} \int_{0}^{T} V_{1}(\tau) \sin \left(m_{1} \tau\right) d \tau \\
& I_{1} a_{1 m}\left(C_{m n 1} \cos a_{m n l}\right)+\ldots+I_{n} a_{n m}\left(R_{n}+C_{m m n} \cos \theta_{m m n}\right) \\
& +\int_{1} b_{1 m}\left(-c_{m n 1} \sin t_{m n !}\right)+\ldots+I_{n} b_{n m}\left(-c_{m m n} \sin *_{n m m}\right) \\
& =\frac{\omega_{1}}{\pi} \int^{T} v_{n}(\tau) \sin \left(m \omega_{1} \tau\right) d \tau .
\end{aligned}
$$


There will also be $N$ equations of the form of eq. (44), one for each of the $n$ coils:

$$
\begin{aligned}
& I_{1} a_{1 m}\left(c_{m 11} \sin \phi_{m 11}\right)+\ldots+I_{n} a_{m=1}\left(c_{m 1 n} \sin \phi_{m 1 n}\right) \\
& +I_{1} b_{1 n}\left(R_{1}+c_{m 11} \cos \phi_{m 11}\right)+\ldots+I_{n} b_{m m}\left(c_{m 1 n} \cos \phi_{m 1 n}\right) \\
& =\frac{\omega_{1}}{\pi} \int_{0}^{T} v_{1}(\tau) \cos \left(m_{1} \tau\right) d \tau \\
& \vdots \\
& I_{1} a_{1 m}\left(c_{m n 1} \sin \phi_{m n l}\right)+\ldots+I_{n} a_{n m}\left(c_{\operatorname{man}} \sin \phi_{m m a n}\right) \\
& +I_{1} b_{1 m}\left(c_{m n 1} \cos \phi_{m n 1}\right)+\ldots+I_{n} b_{n m}\left(k_{n}+c_{m \times n} \cos \phi_{m n n}\right) \\
& =\frac{\omega_{1}}{\pi} \int_{0}^{T} V_{n}(\tau) \cos \left(m_{1} \tau\right) d \tau .
\end{aligned}
$$

Equations (45) and (46) provide 2.1 inearly independent equations to determine the $2 n$ coefficients, $I_{1} a_{1 m}, \ldots, I_{n} a_{n m}, I_{1} b_{1 m}, \ldots, I_{n} b_{n m}$, for the single frequency component, $m w_{1}$. A similar set of $2 n$ equations must be solved for each of the frequency components in the pulse.

The d.c. component of current in the q-th coil will be

$$
\frac{a_{q o} I q}{2}=\frac{\omega_{1}}{4 \pi R_{q}} \int_{0}^{T} v_{q}(\tau) d \tau .
$$

There will be fust $N$ equations of this type to be solved. 


\section{Oriving Voltages}

In equations (43) through (47), it is assuned that the voltage $v_{q}(\tau)$ applifed to the $q$-th coil is a knom function of time, as is usually the case. For the charge-up of a coil, the voltage would be a rap function, as shown in Fig. 6.

ORNL-DWG 75-10666

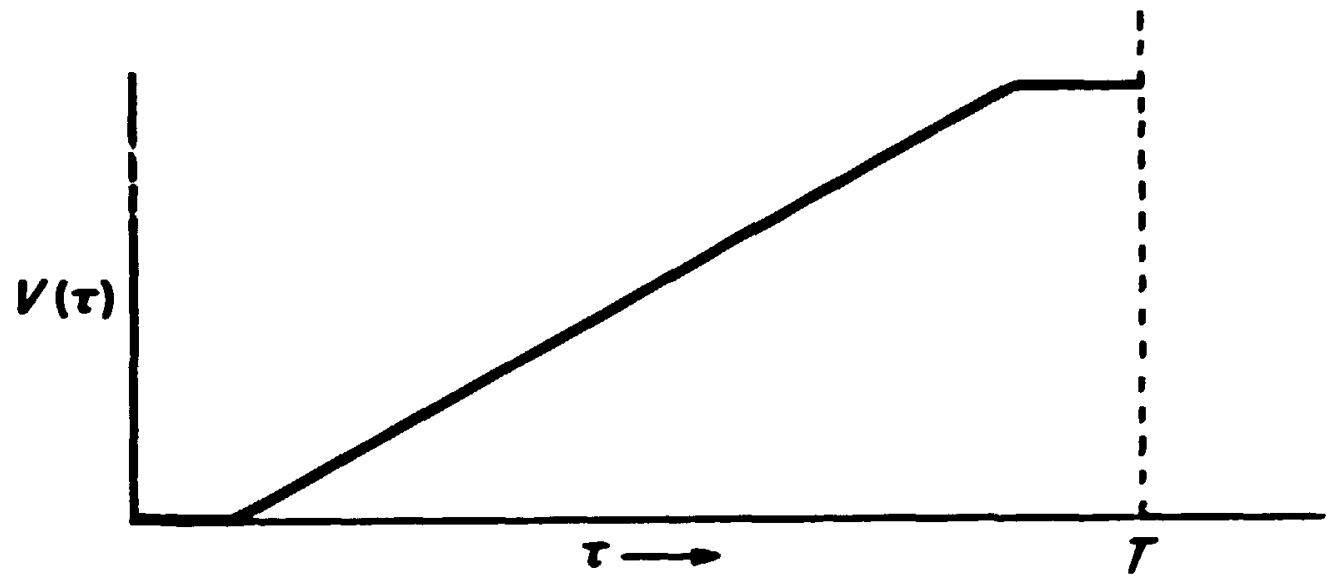

fig. 6. Charging a Coil with a Voltage Ramp.

We can also simulate the turn off of the coil with a voltage step. When the coil goes normal, the current is dumped into a dup resistor. As far as the cotl and coupled circuits are concerned, this is equivalent to a single turn-off pulse of the voltage, $V-(\tau)$, as illustrated in Fig. 7. There is no difference in the voltage and current at point a between the two circuits. The value of $V^{2}(\tau)$ is $V^{-}(\tau)=V(\tau)+I R_{\text {dump }}$. The only real difference is that the voltage that would be dropped across $I R_{\text {dump }}$ is saved by the switch, reducing the power required by the voltage source. 


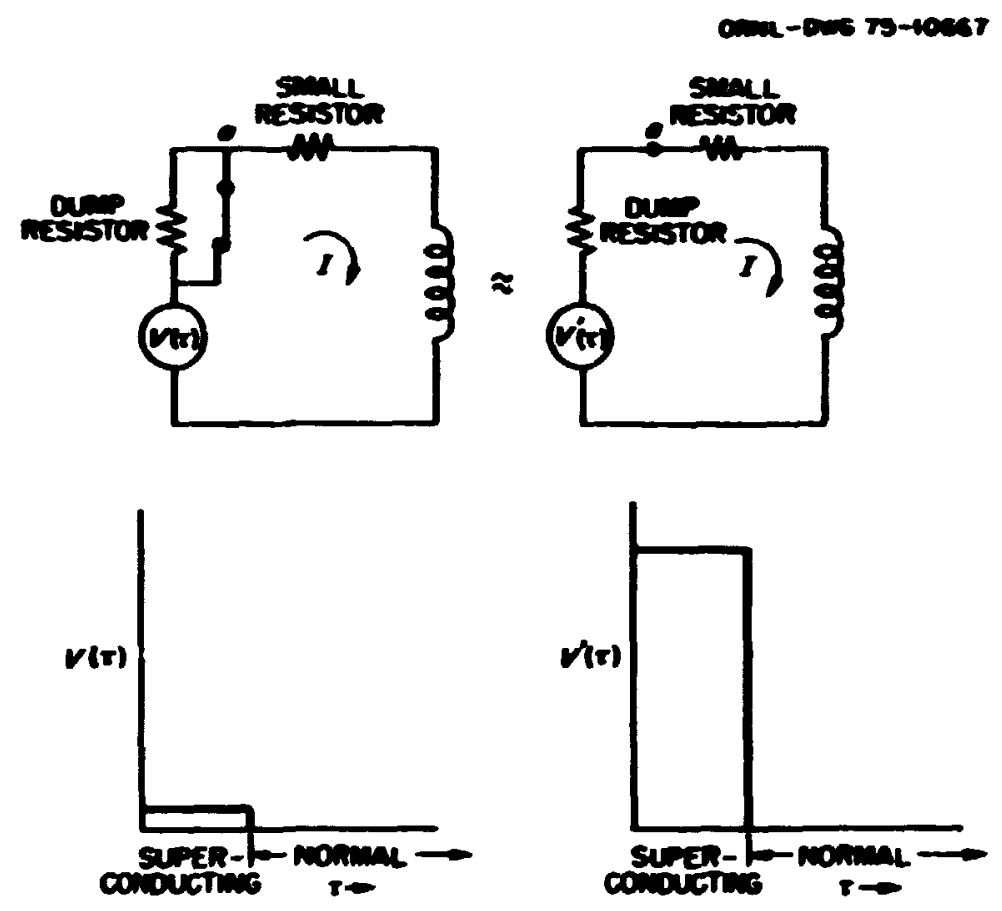

Fig. 7. Equivalent Dumping of Current in Coil.

Once the voltage functions, $v_{q}(\tau)$ are known or simulated, we can obtain the current coefficients, which in turn will give us the current in the various circuits. From these currents we can then calculute all of the other parameters, such as forces, eddy currents, and power dissipated. 
IV. Pesinents of the voricos Pnertics

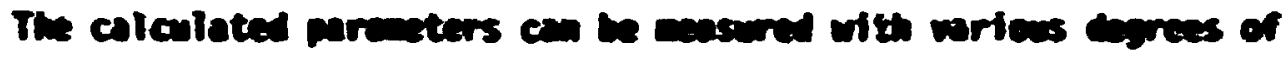
ecarecy and difficulty ustion mols constructed of a stallar woterial

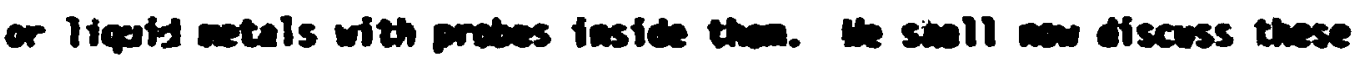
nesserements.

\section{A. Eety Correat vensity}

This can the measured by putt'ng a current mele in mals containimg mercury or mod's metal. Monever, the current prete will waset the field to a certain extent in the region mar the probs. The current is

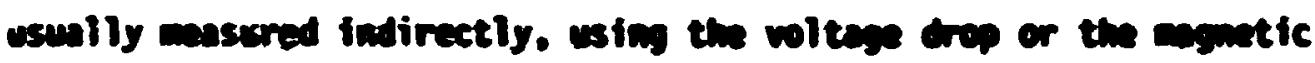
field.

\section{Eddy Current Power}

The total power can be deternitued by measuring the power consinad in the coil. The instantaneous pewer generated in a sinll section of the shielding can be detennined by mesuring temperature changes on the surface of the conductor using infrared techutanes or by using the temperature coefficient of the metal's resistivity (masured with an eddy current prowe) or by usions thenmocouples instide the metal. The latter masurament techinique would probably influence the resuits more than the others, but it could be applied to the interfor of the conductor. All three of these techniques depand on the shielding hating, mich depends in turn on the gecinetry, thenmi conductivity and hast capacity of the model. 


\section{Musete fteld}

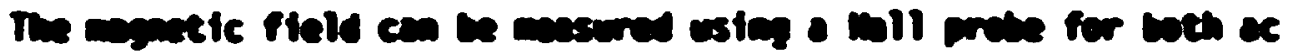

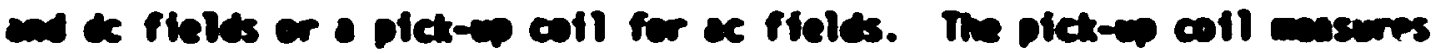

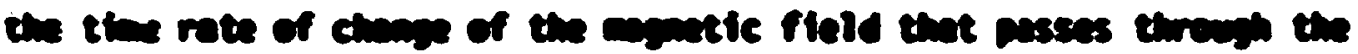

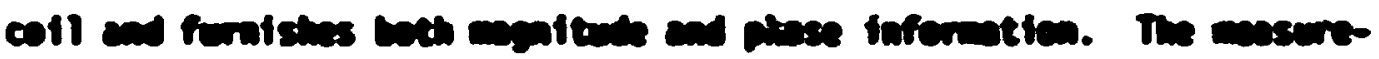

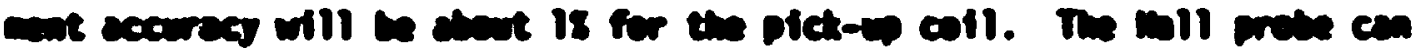

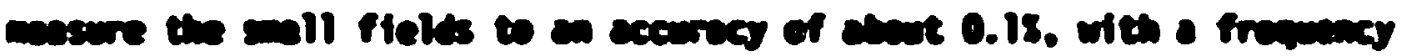

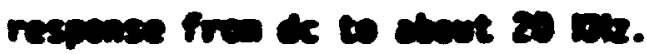

\section{Fence Demsity}

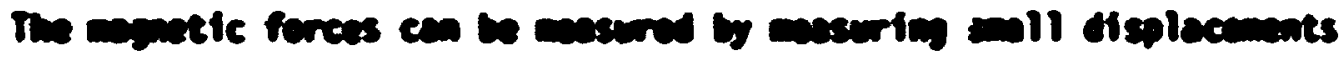

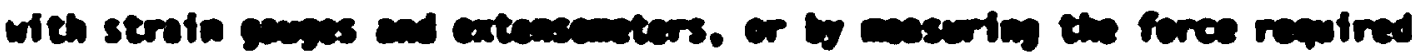

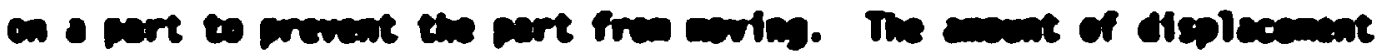

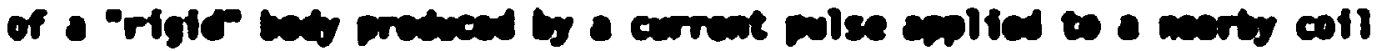

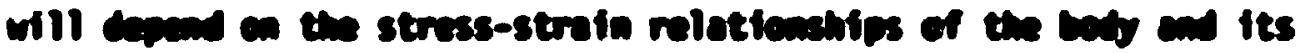

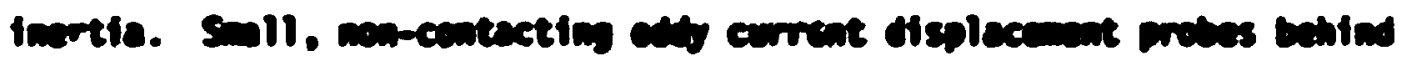
the part could masure e displecenent op to 2010 u in with a recolution

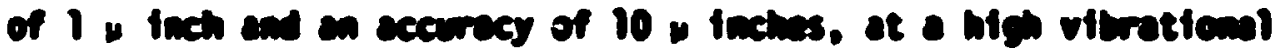
fropency.

\section{E. Voltages in Cireutts}

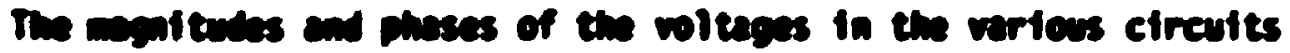

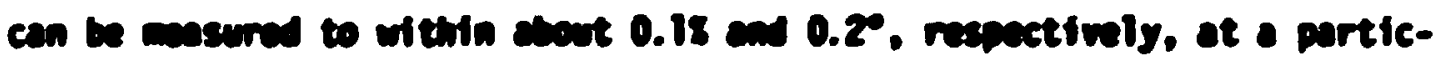

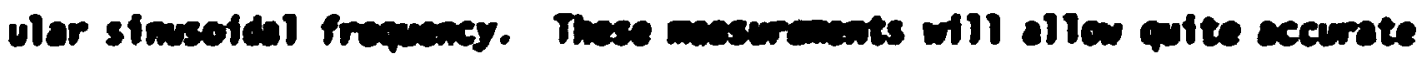

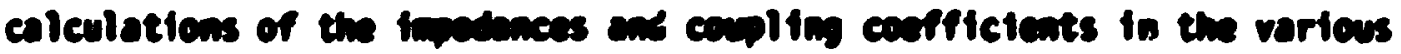


circutes. The mast accurate range of masureantes is in the 50 in the 10 tite rang. The tim-witage relationship for a mise can be nasured

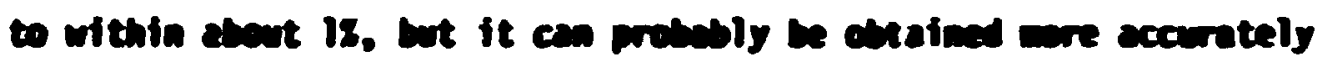

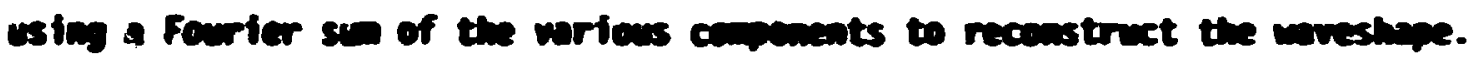

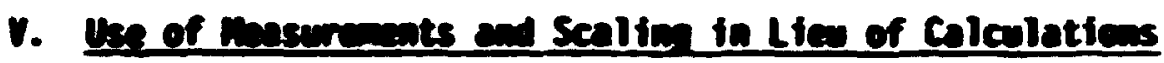

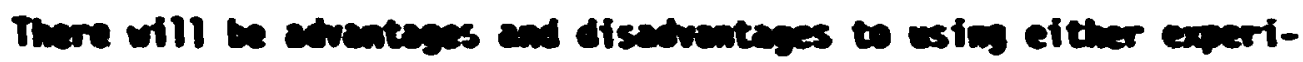
nental masenrmants or murical calculations. A list of several of these consicarations is given below.

\section{A. Moventeges of masurrements}

1. Thay will be reapirad anduce to vertfy the calculations.

2. In many fostances the masurements will be wive eccorate then the caleviations. In particular, for cases mure we can we the results of a single fropuency maserement, the massorenents will be more accurate for quantities such as witages, total bipluse, and total power.

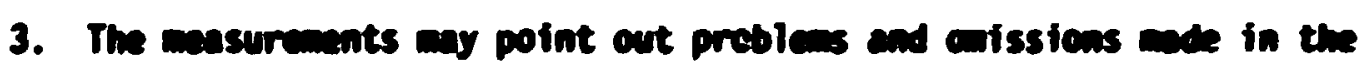
calculation.

4. The mesurements way be cheaper than the 3-dimensfonal relarations.

\section{B. Advantages of Calculations}

1. The celculations thanselves will not introuce crrors into the models as the measuraments do. 
2. It is the coly un to obtain sem ensurers, such as the force

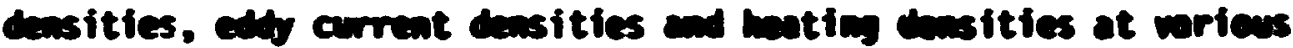
pleces inste the motal.

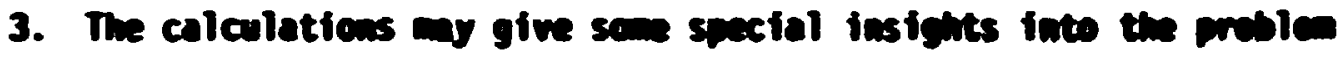
that the measurvments weild wiss. such as mure would be the best

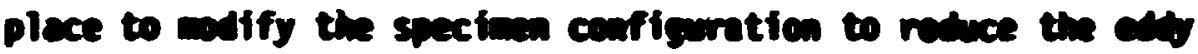
curreats.

In ectual prectice, the the technigues will probsily complement each other to sene extent.

\section{Experimantal Verification of Scalies}

There have been a muber of experimental veriffeations of the scaling of foduction problens. All of the standard edty current calculations are scaled, with the scaling factors introduced as autipliters after all the muerical calculations have been performed usiag dimensionless functions. Therefore, any experinental verification of the calrulatfons also verifies the scaling.

We have made a series of impedance measurements and calculations on colls of four different sizes and with different numbers of turns in the presence of conductors with the results shown in Table 1.

The four colls varied in mean radius from 0.30 in. to $1.20 \mathrm{in.}$, and the test frequency and liftoff were varied to keep the product uno $R_{5}{ }^{2}$ and the normalized liftoff as nearly constant as possible. However. there were stfll variations, as show by the standard deviations of the wuar ${ }^{2}$ and Ifftoff, which contribute to the impedance variations. The 
Table 1. Normalized Coil Impadance for Four Colls frem 0.30 to $1.20 \mathrm{fn}$. Mean Radius as a function of $w_{0} R_{5}{ }^{2}$ and Hermalised Lift-off.

\begin{tabular}{|c|c|c|c|c|c|c|c|c|c|c|c|}
\hline \multirow[b]{2}{*}{ woR ${ }_{5}^{2}$} & \multirow[b]{2}{*}{$s \bar{x}$} & \multirow[b]{2}{*}{ Lift-off } & \multirow[b]{2}{*}{$s \bar{x}$} & \multicolumn{4}{|c|}{ Measured } & \multicolumn{2}{|c|}{ Colculated } & \multicolumn{2}{|c|}{8 Differenes } \\
\hline & & & & $\operatorname{lm}_{n}$ & $S \bar{x}$ & $R \mathbf{I}_{n}$ & $s \bar{x}$ & & & $\ln _{n}$ & $R 1_{n}$ \\
\hline $\begin{array}{r}3.122 \\
8.742 \\
24.98 \\
78.10 \\
334.13 \\
874.20\end{array}$ & $\begin{array}{l}0.007 \\
0.029 \\
0.081 \\
0.36 \\
1.16 \\
2.97\end{array}$ & 0.0473 & 0.0001 & $\begin{array}{l}0.9990 \\
0.8250 \\
0.7343 \\
0.6427 \\
0.5703 \\
0.5364\end{array}$ & $\begin{array}{l}0.0310 \\
0.0180 \\
0.0016 \\
0.0012 \\
0.0005 \\
0.0024\end{array}$ & $\begin{array}{l}0.07 c 5 \\
0.1312 \\
0.1300 \\
0.1069 \\
0.0510 \\
0.0437\end{array}$ & $\begin{array}{l}0.0240 \\
0.0047 \\
0.0005 \\
0.0017 \\
0.0055 \\
0.0011\end{array}$ & & & $\begin{array}{l}+9.98 \% \\
-4.89 \\
+8.93 \\
+7.89 \\
+1.03 \\
+0.04\end{array}$ & $\begin{array}{l}-23 . \\
+1.8 \\
+2.8 \\
+8 . \\
-0 . \\
+5 .\end{array}$ \\
\hline $\begin{array}{r}3.122 \\
8.742 \\
24.98 \\
78.10 \\
334.13 \\
874.20\end{array}$ & $\begin{array}{l}0.007 \\
0.029 \\
0.081 \\
0.36 \\
1.16 \\
2.97\end{array}$ & 0.0946 & 0.0002 & $\begin{array}{l}0.9175 \\
0.8410 \\
0.7693 \\
0.6917 \\
0.6339 \\
0.6070\end{array}$ & $\begin{array}{l}0.0105 \\
0.0112 \\
0.0018 \\
0.0008 \\
0.0017 \\
0.0018\end{array}$ & $\begin{array}{l}0.05 e 2 \\
0.105 \\
0.1053 \\
0.045 \\
0.047 \\
0.0351\end{array}$ & $\begin{array}{l}0.0035 \\
0.0005 \\
0.0005 \\
0.001 \\
0.0005 \\
0.0011\end{array}$ & & & $\begin{array}{l}-0.78 \\
-0.09 \\
+0.76 \\
+0.30 \\
+0.46 \\
-0.30\end{array}$ & $\begin{array}{r}-20.48 \\
-3.60 \\
+2.83 \\
+2.92 \\
-0.01 \\
+7.01\end{array}$ \\
\hline $\begin{array}{r}3.122 \\
8.742 \\
24.98 \\
78.10 \\
334.13 \\
874.20\end{array}$ & $\begin{array}{l}0.007 \\
0.029 \\
0.081 \\
0.36 \\
1.16 \\
2.97\end{array}$ & 0.1892 & 0.0004 & $\begin{array}{l}0.9225 \\
0.8593 \\
0.8245 \\
0.7707 \\
0.7735 \\
0.7140\end{array}$ & $\begin{array}{l}0.0345 \\
0.0135 \\
0.0013 \\
0.0003 \\
0.0019 \\
0.0027\end{array}$ & $\begin{array}{l}0.0410 \\
0.0317 \\
0.0330 \\
0.0593 \\
0.0028 \\
0.0229\end{array}$ & $\begin{array}{l}0.0135 \\
0.0089 \\
0.0010 \\
0.0016 \\
0.0003 \\
0.0003\end{array}$ & & & $\begin{array}{l}-1.67 \\
-1.29 \\
+0.65 \\
+0.38 \\
+.12 \\
-0.03\end{array}$ & $\begin{array}{r}-27.03 \\
+0.83 \\
+9.83 \\
+4.77 \\
-1.21 \\
+6.83\end{array}$ \\
\hline $\begin{array}{r}3.122 \\
8.742 \\
24.98 \\
78.10 \\
334.13 \\
874.20\end{array}$ & $\begin{array}{l}0.007 \\
0.029 \\
0.081 \\
0.36 \\
1.16 \\
2.97\end{array}$ & 0.3785 & 0.0006 & $\begin{array}{l}0.9370 \\
0.9293 \\
0.8933 \\
0.8447 \\
0.8470 \\
0.8382\end{array}$ & $\begin{array}{l}0.0010 \\
0.0050 \\
0.0019 \\
0.0003 \\
0.0024 \\
0.0021\end{array}$ & $\begin{array}{l}0.0292 \\
0.0533 \\
0.0478 \\
0.0322 \\
0.0164 \\
0.0115\end{array}$ & $\begin{array}{l}0.0182 \\
0.0011 \\
0.0016 \\
0.0021 \\
0.0003 \\
0.0005\end{array}$ & & & $\begin{array}{l}+3.11 \\
+0.68 \\
+0.48 \\
+0.17 \\
+0.40 \\
+0.22\end{array}$ & $\begin{array}{r}-28.08 \\
+16.70 \\
+17.44 \\
+9.80 \\
-1.21 \\
+6.48\end{array}$ \\
\hline
\end{tabular}

$S \bar{x}=$ standard deviation of the mean. 
mobers of turns were all different, but were also el iaiated by monali2ation. The inpedences given in colvens 5 and 7 are manlized by dividing by the coil indectance in air. The ingertant pantities to notice in the toble are the follarimg: (1) the stambry deviations of the real and ingianry parts of the monelized ingenances (colcuss 8 and 6), wich should be zero if the scalfing. censtruction, and masurnats were perfect; (2) the experifinental and calculated values of the real and ianginary parts of the coil inpedances for the various liftoffs (colums 7, 5, 10, 9). Wote that, except for the first tho values of wor $5^{2}$, for mich the frequencies wre so low that the measurements were not very accurate, the standard devfations in colums 6 and 8 are very sall, indicating that the four different coils all gave the same results. This indicates the validity of the scaling laus mich keep wuoR ${ }_{5}^{2}$ and the normalized liftoff constant and factor out the muber of turns of the coils, when the driving coil and the pickup coil are one and the same. The calculated values in colums 9 and 10 are for a coil with normalized dimensions wich are the average of those for the four colls. Since the percentage differences between measured and calculated values seem randomly scattered, it seems that the experimental measurements are most in error, and the variations are generally comparable to the standard deviations of the measurements.

Table II shows how the calculated and measured inductances vary for a large number of coils that have been used in a number of eddy current experiments, using the apparatus shown in Fig. 8. Although the agreenent is quite good for these examples, there have been a few instances where the error was as large as $2 \% . '$ It is suspected in these cases that an error occurred in the number of turns. 


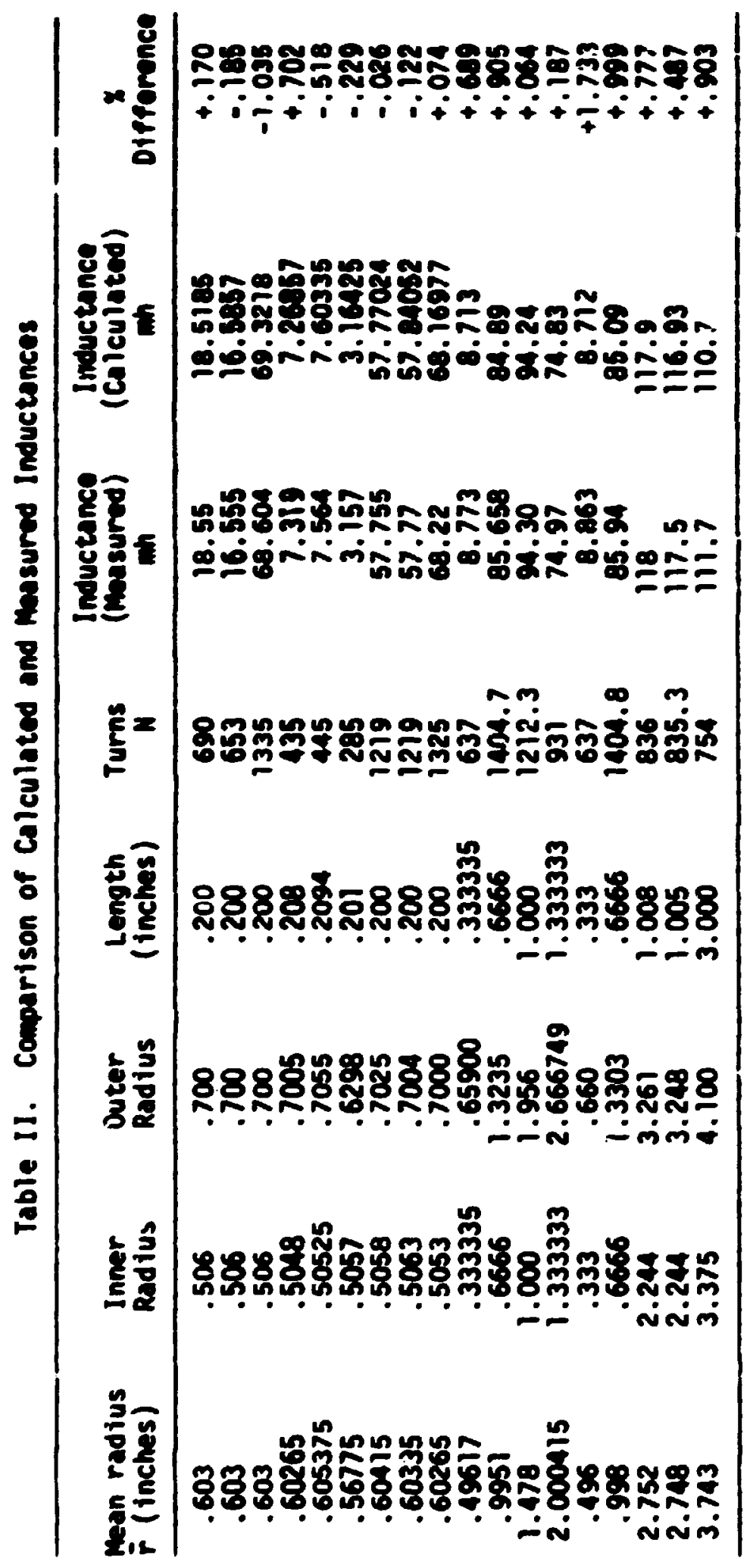




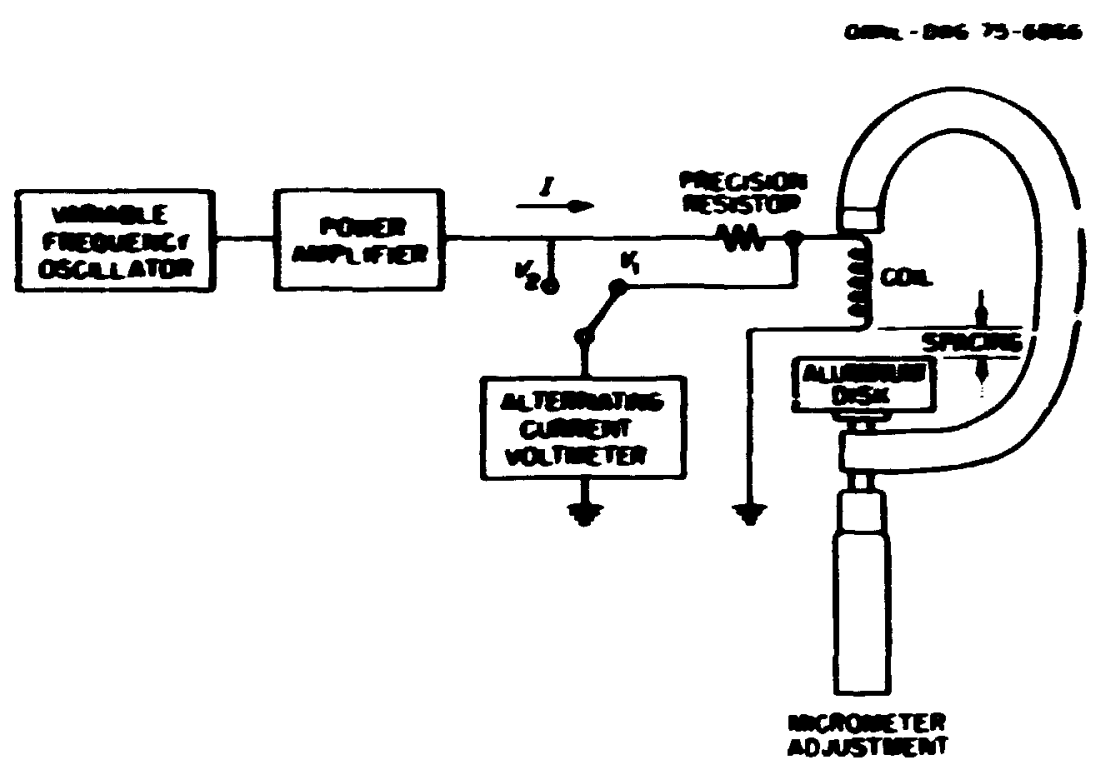

Fig. 8. Diagran of Impedance Measurement Apparatus.

In Table III we show the experimental force measurements for two different size coils with the same shapes, made with the apparatus illustrated in Fig. 9. These measurements again dewonstrate the validity of scaling. The error is relatively large for these measurements, but they were made before more accurate experimental apparatus was available. Note that the forces are given in $10^{-7}$ newtons/(anp-turn) $)^{2}$, indicating the validity of factoring out the number of turns and the driving current. 
Table III. Comprison of Calculated and heasured Eddy Current Forces

\begin{tabular}{|c|c|c|c|c|c|}
\hline $\operatorname{maR}{ }_{s}^{2}$ & $\begin{array}{l}\text { Calculated } \\
\text { Force }\end{array}$ & $\begin{array}{l}\text { Measured } \\
\text { Coil gat }\end{array}$ & $\frac{\Sigma}{\delta}$ & $\begin{array}{l}\text { Masured } \\
\text { - Coil chat }\end{array}$ & $\frac{z}{\text { Difference }}$ \\
\hline \multicolumn{6}{|c|}{ Lift off = .0476 $R_{5}:$} \\
\hline 3.082 & 1.12146 & 1.048 & -6.55 & 1.058 & -5.65 \\
\hline 8.628 & 2.80859 & 2.642 & -5.93 & 2.694 & -4.08 \\
\hline 24.65 & 5.11168 & 4.374 & -7.78 & 4.954 & -3.08 \\
\hline 77.05 & 7.52462 & 6.933 & -7.86 & 7.326 & -2.64 \\
\hline 329.8 & 9.82756 & 8.989 & -8.53 & 9.664 & -1.66 \\
\hline 862.8 & 1C. 7935 & 10.18 & .5 .68 & 10.90 & +0.99 \\
\hline \multicolumn{6}{|c|}{ Liftoff $=.0952 R_{5}:$} \\
\hline 3.082 & .987604 & .9289 & -5.94 & .9540 & -3.40 \\
\hline 8.628 & 2.41421 & 2.265 & -6.18 & 2.366 & -2.00 \\
\hline 24.65 & 4.29660 & $4.02 !$ & $-6.4 !$ & 4.260 & -0.85 \\
\hline 77.05 & 6.17141 & 5.776 & -6.41 & 6.201 & +0.48 \\
\hline 329.8 & 7.85378 & 7.430 & -5.40 & 7.954 & +1.28 \\
\hline 862.8 & 8.53364 & 8.237 & -3.49 & $8.9: 3$ & +4.46 \\
\hline
\end{tabular}

* Forces in units of $10^{-7}$ newtons/(amp-turn) ${ }^{2}$

* coil $B$ mean radius $=0.6063$ in.

* Coil $C$ mean radius $=0.9023$ in. 


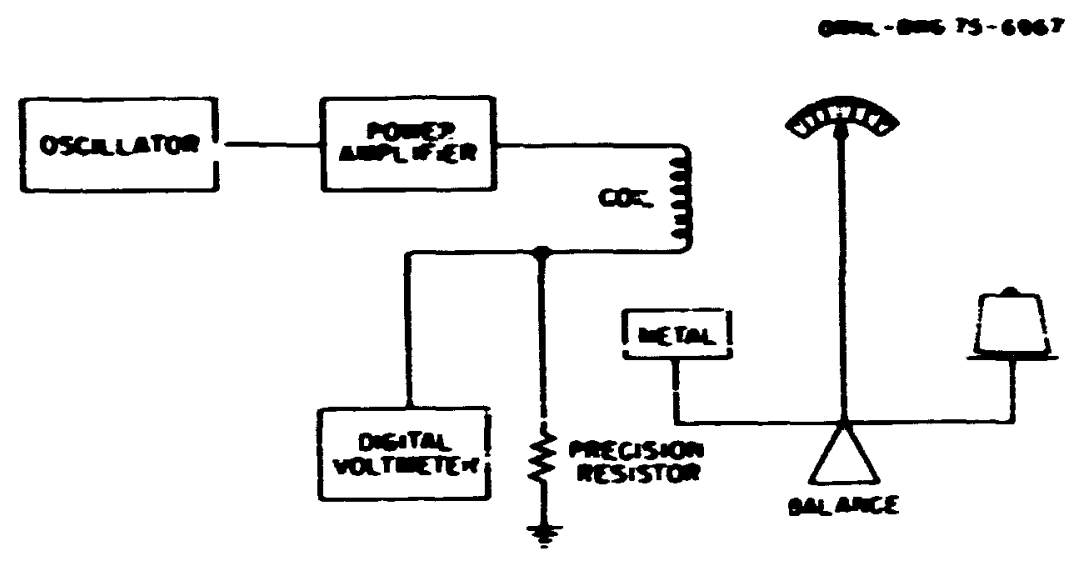

Fig. 9. Diagran of Force Measurement Apparatus.

\section{vII. Sumary and Conclusions}

The concepts of scaling will allow experimental measurements ade on relatively sall models to be extended to full size models. There will be an optiman size for a mode? to obtain the most accurate results at the least expense. If the model is too small, it will be expensive to hold the coil and conductor dimensions to the desired tolerances, and the measuring apparatus will be difficult to install. On the other hand, if the model is too large, it will consume an expensive amount of materials and construction labor. A model wich uses coils that are 2 to 4 inches in dianeter would probably give the best results at the low.jt cost.

The experimental measurements made thus far denonstrate the validity of scaling. However more accurate and additional measurenents (such as the voltage coupling coefficients for multiple coils) need to be made to provide more confidence. 
thile the scaling can provide quite valuable desigr. paraneters, it will not furnish all of the answers. The best results will probably come from a balanced program of matehatical models and experimental models with comarisons between numerical calculations and experimental measurements. 


\section{References}

1. C. V. Dodd, "Eddy-Current Impedance Calculated by a Relaxation Method," pp. 300-314 in Proceedings of the Symposium on Physics and Mondestructive Testing, Southest Research Institute, San Antonio, Texas (1963).

2. C. V. Dadd, a Solution to Electronagnetic Induction Problems, ORM-TH-1185 (August 1965). M.S. Thesis, The University of Tennessee.

3. C. V. Dodd, Solutions to Electronagnetic Induction Problems, ORIL-TH-1842 (June 1967). Ph.D. Thesis, The University of Tennessee.

4. J. Melson Tunstall and C. V. Dodd, III, A Computer Progrom to Solve Eddy-Current Problems, K-1740 (Aprii 8, 1968).

5. C. V. Dodd and W. E. Deeds, "Computer Design of Eddy-Current Tests," p. 199 in Proceedings of Fifth International Conference on Bondestructive Testing, Montreal, Canada, The Queen's Printer, Ottama, Canada (1965).

6. C. V. Dodd, W. E. Deeds, and W. G. Spoeri, Optimizing Defect, Detection in Eddy-Current Testing, Materiale Evaluation 29, 59 (1971). 
7. C. V. Dodd and M. A. Simpson, Jr., Measurenents of Small Magnetic Permeability Changes by Eddy Current Techniques, Materials Evaluation 29, 217 (1971).

8. C. V. Dodd and Y. A. Simpson, Jr., Thickress Measurenents Using EdC'y. Current Teckniques, GRol-TH-3712 (1972).

9. C. V. Dodd, C. C. Cheng, C. H. Mestor, and R. B. Hofstra, Design of Induction Probs: for Mecourement of Liquid Metais, ORM-TM-4175 (1973).

10. C. V. Dodd, J. H. Smith, and H. A. Simpson, Eddy-Current Evaluation of theclear Control Rods, ORNL-TM-4321 (1973).

11. C. Y. Dodd, W. E. Deeds, .J. H. Luquire, and W. 6. Spoeri, Same Eddy-Current Problems and Their Integral SoIutions, CRII-4384 (April 1969).

12. F. O. Mundt, Eddy-Current Mearurement with a Coil Encireling a Two-Conductor Rod, Y-1787 (Apri1 1971).

13. J. T. Hill, Clad-Thickness Measurements Using Dual-Frequency Eddy Current, Y-1970 (May 1974).

14. C. C. Feng, H. E. Deeds, and C. V. Dodd, Analysis of Eddy-Current Flameters, Joumal of Applied Physics (July 1975). 